\title{
Stress Management Techniques of ITES Employees
}

\author{
Rajandran KVR
}

\begin{abstract}
In this modern trendy world in which stress has become an essential part not only in human beings and organisations. A substantial percentage of Americans works very long hours by one estimate more than $26 \%$ of men and more than $11 \%$ of women worked 50 hours or more per week. This research was an attempt to identify the stress management techniques among the ITES employees in Trichy city. Multi stage sampling method adopted for this descriptive study and 278 was the sample size. Descriptive analysis for percentage, frequencies and regression analysis carried out on data using SPSS. The result shows stress relievers. These stress busters had positive influence on stress level of ITES Employees and it also generates the stress free work environment at Trichy.
\end{abstract}

Index Terms: BPO, ITES, KPO, Stress Relief Technique

\section{INTRODUCTION}

The present computable and technological world aspires to the height and even to reach beyond the stress by innovative and inventing methods of business, marketing and human resource employment etc. Hence the drive to do the best causes stress and leads to achievement or sometimes illhealth etc. The word 'stress' is predominant and inevitable to all human beings and also animals. It is originated from a latin word "Strictus" which means tightened, compressed and closely associated with physics for they used this previously. Man is a social animal. He has to live in groups and be dependent running an organization cause them stress. Our scientific and innovative competitive world predominantly relates to stress, the common word uttered from child to man in all walks of life. Many companies target their employees with time and yield to promotion. Many ITES Employees are stressed because of their companies drive, aspiration and yield. Yet, they adopt some stress management techniques to achieve their goals. Performing plenty of exercise taking good intake, space for rest and relaxation which help to live a healthy life style, prayer, yoga, meditation and breathing exercise help them to live healthy style which reduces the stress. Above all people accepting the change as part and parcel of their life. Nothing but change is standard, Individuals must believe in themselves and develop to cultivate a stress free life by reading books, viewing good videos, listening good music and participating in creative visualization (Darton 2012)

Eustress or positive stress is expressed as stress which makes employees to perform one step higher and much job satisfied(words of appreciation-feels elevated) Negative stress or distress ends in physical and psychological illness (scolding-headache). In a stress free work environment, employees work with co-operation active participation,

Revised Manuscript Received on July 05, 2019

Rajandran KVR, Department of Management Studies, Periyar Maniammai Institute of Science \& Technology, Thanjavur, India. smiling and plan to work perfectly in a short time to bring forth their calibre. Employee counselling helps the employee and the employer for good interaction and clarity ends in active problem solving.

Stress Management is a collection of various methods of techniques aimed to control a stress level of a person to progress. Work life balancing is equalizing employees personal and professional climate. It is an essential approach in the business world. Communication between management helps them to attain their goals in the work place. Recognizing or honouring employees increase the level of exercise and promote values

\section{REVIEW OF LITERATURE}

Jac et.al (2000) researched on for the benefits of Interventions in work-related stress, 48 studies were done with sending 3736 participants. The researchers found individual cop skills in a job that allows them to exercise those skills.Every organization focused interventions aimed at increasing control potentials.

Sudhkar and Sudha Rani (2010) inspected on work life balance in ITES sector. The research carried only ITES employees in the HR Department. The sample size was 150 employees. The researchers used descriptive analysis, found the work life balance options, diagnose in this research was flexible working hours. Family/ Friends program career guidance, professional counselling and life skill program.

Joseph et.al (2011) evaluated an expedition under stress and its management stages of stress by Hans Selye were alarm reaction, resistance and exhaustion types of stress were acute stress episodic acute stress /time stress, chronic stress anticipatory stress situational stress. Encounter stress hyper stress bears stress psychological stress and physiological stress. The researcher analyzed alter accept to adapt assertive to the stressful event.

Kousalya and Revathi (2013) experimented on the employee's motivation and stress management. The researchers used 10 questions to all employees. The researcher proved employees were the heart and soul of every organization; employee motivation varies from company to company. Constant motivation helps in retaining employees in their organization.

Jessica(2015) evaluated counselling to reduce stress and anxiety. The research carried out participants in counselling services. The sample size was 5. The researcher used Cohen perceived stress scale (CPSS). The researcher found participants believed that counselling helped them to reduce stress and anxiety. Build hope in the individuals lives taught, coping strategies for managing stress and anxiety. 
Parminder (2015) studied on gender and age correlates work-life balance. The research dealt with working professionals was in IT and ITES industry. The sample size was 308. The researcher used work life balance scale and statistical tools. The researcher investigated that the female compared to males. Female plays a dual role- home maker and earners.

\section{MATERIALS AND METHODS}

\section{A. Statement of the Problem}

In all organization employees face the stress due to their work environment .If the stress is not control or reduce it may cause physical and mental problem. Especially the ITES employee working in shift system with workload, environment and exposure to computers do contribute stress among them. The organization has to manage the stress level through stress management program which will assist the employees to reduce their stress.

\section{B. Scope of the Study}

Every employee reacts to stress in a different way, by realising the nature of individual responses useful for battling by oneself and others. Reduction or displacement of stress is necessary for the health of an individual. The study will be helpful to extend certain suggestions to expose the role of stress assessed from the ITES employees.

Special capability in stress management enables the individual to deal or adjust-manage the stressful situations instead of avoiding. Strategies for stress management, body-mind and mind-body relaxation exercise and to improve both physical and mental health of employees to adopt certain managing strategies for stress relief and employing service counsellor will be more useful. Many strategists can involve in managing stress in the workplace.

\section{Objective of the Study}

The general objective of the present study is to understand the stress relief techniques among ITES employees in Trichy city

- To study the effectiveness of the stress management program opted by the ITES companies

\section{Area of the study}

Among the various service sectors, ITES sector in Trichy city is deliberately selected for the present study. The ITES companies in Trichy are randomly selected and the ITES employees in the ITES companies are also randomly selected. Thus, the sector and study area is purposively particular followed by companies and ITES employees have been selected stage by stage adopting Multi Stage sampling techniques. The data and information is collected from ITES employees through Pilot Study, structured interview schedule by direct interview method. The data and information have been collected from 278 ITES Employees of ITES companies and pertain to the year 2017-2018.

\section{E. Sources of Data}

Primary data collected from the employees meeting personally over mobile and e-mail interview with pretested, structured questionnaire. The secondary data collected from perceive higher interference of work with personal life as

various sources like library books, journals, research papers, thesis, reports, conferences, magazines, newspapers and web sites.

\section{F. Sampling Technique and Sample Size}

There are 50 registered ITES companies presently operating in Trichy City. There are 5560 ITES Employees are working in ITES Sector in Trichy Town. Multi-Stage sampling method has been employed for collection of data. At First step - fifteen companies were chosen. At Second step, the number of respondents was established from each company based on their work experience. At Third steps Employees response to research questionnaire.

\section{G. Sampling Population}

Sample size of 400 was planned for the research, but only 300 responses were received from the ITES employees of Trichy city. Among them, 22 employees properly not submitted the data so researcher settles with 278 responses which is Rao Software. The sample comprised of ITES employees who worked in a busy environment for more than 2 years. ITES employees worked in different ITES sectors, had experiences with the pressure managing working environment, and were the targeted samples.

\section{H. Data Analysis and Statistical Techniques}

The data analysis has been performed by using IBM SPSS20 (Statistical Package for Social Sciences).

In order to understand the demographic feature, Stressor causing Environmental Factors, Organizational Factors and Individual Factors and Stress Management in various Industries and Stress Management techniques of ITES Employees in ITES Companies, the percentage analysis and frequency distribution have been worked out Cronbach's alpha reliability test was used to test the reliability of question used for their research

The measure of inside consistency that was used as a part of this survey was Cronbach's coefficient Alpha. The figured Cronbach's $\alpha$ coefficients if higher than 0.80 which is viewed as a high inner consistency.

A high Cronbach's alpha esteem gives great sign of thing covariance and testing space has been caught satisfactorily (Churchill, 1970).

\section{RESULTS AND DISCUSSION}

\section{A. Socio-Categorical Background of ITES Employees}

Table 4.1 showed the Socio-Categorical background of ITES employees. Out of total respondents 278, $66.5 \%$ were male and $33.5 \%$ were female employees. Table 4.1 described that age group of 20-25 years were major $(79.9 \%)$ participant, Second were $25-30$ years (19.8\%) and followed by $30-35$ years (4\%). It was evident that most of the respondents had completed their UG $(80.6 \%)$ followed by PG $(13.3 \%)$, and Diploma $(6.1 \%)$. Majority of the employees experience were $20-25(78.8 \%)$ years of and their 0-5 years of experience and $5-10$ years of experience (21.2\%). Majority of the employee's

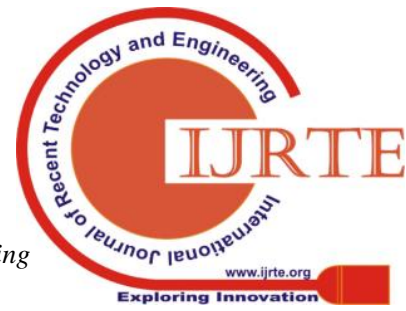


income were Rs 5000- 10000(37.1\%) second were Rs 10000-15000 (33.8\%) third were below Rs 5000(20.1\%) and Rs $15,000-20000(9 \%)$ Majority of their family is Nuclear(70.1) and Nuclear (29.9) Majority of the employees Place of origin were urban $(69.4 \%)$ and Semi urban were $(28.8 \%)$ and Rural (1.8\%) Demographic value gender was used to find the invariance across genders group.

\section{Table 1: Socio - Categorical Description of ITES Employees}

\begin{tabular}{|c|c|c|c|c|c|}
\hline Categories & $\begin{array}{l}\text { Freq } \\
\text { uency }\end{array}$ & $\begin{array}{c}\text { Percent } \\
\text { age }\end{array}$ & Education & \begin{tabular}{|c|} 
Frequenc \\
$\mathbf{y}$
\end{tabular} & Percentage \\
\hline Gender & & & $\begin{array}{c}\text { Diplo } \\
\text { ma }\end{array}$ & 20 & 4.7 \\
\hline Male & 185 & 66.5 & $\overline{\mathrm{UG}}$ & 309 & 71.9 \\
\hline Female & 93 & 33.5 & PG & 74 & 17.2 \\
\hline Age & & & Income & & \\
\hline $20-25$ & 222 & 79.9 & Below 5000 & 56 & 20.1 \\
\hline $25-30$ & 55 & 19.8 & $5000-10000$ & 103 & 37.1 \\
\hline $30-35$ & 1 & 4 & $10000-15000$ & 94 & 33.8 \\
\hline & & & $15,000-20000$ & 25 & 9.0 \\
\hline Education & & & Experience & & \\
\hline Diploma & 17 & 6.1 & $0-5 y r s$ & 219 & 78.8 \\
\hline UG & 224 & 80.6 & $5-10 \mathrm{yrs}$ & 59 & 21.2 \\
\hline PG & 37 & 13.3 & Place of Origin & & \\
\hline Family & & & $\begin{array}{l}\text { Urb } \\
\text { an }\end{array}$ & 193 & 69.4 \\
\hline Joint & 83 & 29.9 & Semi- Urban & 80 & 28.8 \\
\hline Nuclear & 195 & 70.1 & $\begin{array}{c}\text { Rur } \\
\text { al }\end{array}$ & 5 & 1.8 \\
\hline
\end{tabular}

The analysis of collected data had been carried out in two stages. In the second study, the data collected in second part had been analyzed. It had been mainly carried out to answer the second objective. Stress were Irritation(IRR), Unhappy(UH), Missing my family(MF), No appetite(NA) and Difficulties in Sleeping(DS).They were six (6) variables used in the study of Stress Reliever techniques for reducing stress amongst the ITES Employees of Trichy. The Stress Reliever along with six (6) Stress reliever scale items were known as independent variable and Stress was dependent variable. Therefore, the researcher used one dependent variable and six independent variable used for this study. The researcher selected variables based on the psychometric qualities expressed by ITES Employees of Trichy city and from a review of literature.

\section{B. Framework of Stress and Stress Reliever Model}

The framework of Stress and Stress Reliever Model consists of one independent factor with six (06) independent subscale items. The independent factor was Stress relievers. Further this single factor had six subscale items. The sub scale items were improvements of Stress Free environment (SFE), Positive Stress (PS), Counselor (CSR), Stress Relief Technique (SRT),Work Life Balance (WLB) and Employee Recognition (ER)for the ITES Employees.

\section{Observed Variables of Stress and Stress Relievers}

Table 2 Showed observed variables of Stress and Stress relievers models, collected for the analysis purpose. The table showed frequency and percentage of opinions on Likert Scale. The figures in the parentheses and percentage total.

Table 2: Variables of Stress and Stress Relievers

SDA: Strongly Disagree; DA: Disagree; NANDA: Neither Agree nor Disagree; SA: Strongly Agree

\begin{tabular}{|c|c|c|c|c|c|c|}
\hline $\begin{array}{c}\text { Observed } \\
\text { Variables }\end{array}$ & $\mathrm{A}^{\mathbf{S}}$ & $\overline{\mathbf{A}}$ & $\begin{array}{l}\text { NAN } \\
\text { DA }\end{array}$ & $\overline{\text { DA }}$ & SDA & Total \\
\hline $\begin{array}{l}\text { Stress Free } \\
\text { Environment }\end{array}$ & $0(0)$ & $0(0)$ & $27(9.7)$ & $127(45.7)$ & $124(44.6)$ & $278(100)$ \\
\hline Counselor & $0(0)$ & $0(0)$ & $28(10.1)$ & $128(46.0)$ & $122(43.9)$ & $278(100)$ \\
\hline Work Life Balance & $0(0)$ & $0(0)$ & $27(9.7)$ & $130(46.8)$ & $121(43.5)$ & $278(100)$ \\
\hline $\begin{array}{l}\text { Employee } \\
\text { Recognition }\end{array}$ & $0(0)$ & $0(0)$ & $23(8.3)$ & $130(46.8)$ & $125(45.0)$ & $278(100)$ \\
\hline Positive Stress & $0(0)$ & $0(0)$ & $28(10.1)$ & $130(46.8)$ & $120(43.2)$ & $278(100)$ \\
\hline Stress Relief Technique & $0(0)$ & $0(0)$ & $18(5.5)$ & $134(48.2)$ & $126(45.3)$ & $278(100)$ \\
\hline
\end{tabular}

\section{Confirmatory Factor Analysis}

The Chi-square value for stress $\&$ stress reliever model was 642 with 520 at significant $\mathrm{p}$ value $(\mathrm{p}<0.001)$. Normally a chi-square test conducted to assess how much exactly the models fit the variance in the population. . A significant chisquare may not be problematic if all other fit indices are sufficient (Hinkin, 1997). The acceptable threshold limit scores for goodness of fit are $\mathrm{cmin} / \mathrm{df}<3$, p-value $>.05$, CFI $>.95$, GFI $>.95$ (or $>0.90$ ), AGFI $>0.80 \quad$ RMR $<.09$ RMSEA $<.05$ or .08 and PCLOSE $>.05$ (Hu and Bentler (1999).

Table 3: Variables of Stress and Stress Relievers

\begin{tabular}{|l|l|l|l|l|l|l|l|l|}
\hline $\begin{array}{l}\text { Fit } \\
\text { Statistic }\end{array}$ & CMIN/ & P & CFI & GFI & AGFI & RMR & $\begin{array}{l}\text { RMS } \\
\text { EA }\end{array}$ & $\begin{array}{l}\text { Plos } \\
\text { s }\end{array}$ \\
\hline $\begin{array}{l}\text { Recomm } \\
\text { ended }\end{array}$ & $<3$ & $>.05$ & $>.95$ & $>.95$ & $>.80$ & $<.09$ & $<.05$ & $>.05$ \\
\hline $\begin{array}{l}\text { Stress } \\
\text { Reliever }\end{array}$ & 1.587 & .000 & .982 & .960 & .936 & .040 & .046 & .600 \\
\hline
\end{tabular}

Table 3 described the confirmatory factor analysis result for stress \& stress reliever model. The actual 
value obtained against CMIN/DF 1.587,P .000,CFI .982,GFI .960,AGFI .936,RMR .040,RMSEA .046 and P close .600 are respectively. All the values satisfied the recommended threshold values. Usually cut-off point of GFI is 0.90 . The confirmatory factor analysis showed that proposed model was satisfying the required threshold values and confirmed the goodness of fit of the measurement model stress \& stress relievers. Hence, the stress \& stress reliever model showed an overall acceptable fit. The model is an over identified model. Therefore, confirmatory factor analysis provided empirical support for the development of stress \& stress reliever model.

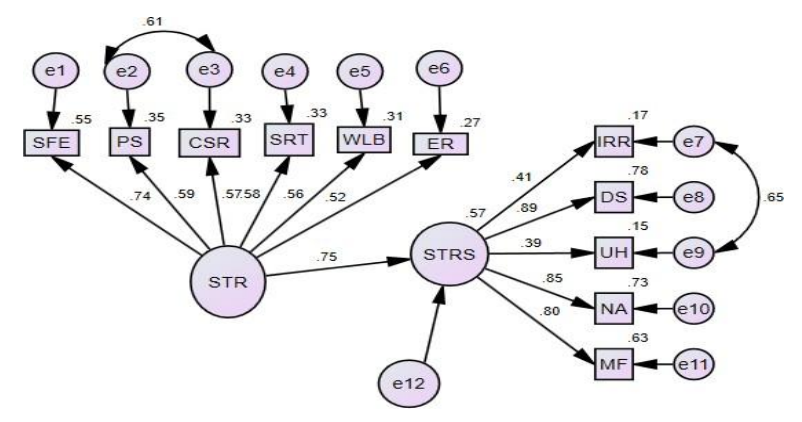

Structural model's validity established through CFA as done for the measurement model. A new covariance matrix computed for SEM of Stress reliever model. Measurement model was different from the SEM, since the measurement model constructs correlated, whereas for structural model the relationships assumed zero. Table 4.19 showed the fit indices of the structural model. As all the values satisfied the prerequisite of threshold values, it confirmed that model had goodness of fit. Hence, it confirmed that the proposed research model fits the data well.

\section{E. Hypothesis Testing}

Every single path in the structural equation model between the variables signified a particular hypothesis. The hypothesized research model exhibited good fit with observed data. The Table 4.20 showed the path coefficients, standard error, critical ratio otherwise known as $t$ value and the related P-value to measure the relationship between the variables for stress and stress relievers model had a direct positive effect on their corresponding subscale items. Highly significant $\mathrm{P}$ values reject the null hypothesis and an insignificant $\mathrm{P}$ value insisted to accept the null hypothesis.

\section{Table 4: Regression Weights Table with $\mathbf{R}^{2}$ from SEM of Stress Reliever}

\begin{tabular}{|l|c|c|c|c|c|c|c|c|}
\hline $\begin{array}{c}\text { Hypot } \\
\text { hesis } \\
\text { path }\end{array}$ & & Estimate & $\mathrm{R}^{2}$ & S.E. & C.R. & P & $\mathrm{H}_{0}$ \\
\hline STRS & $<--$ & STR & 0.754 & .568 & 0.058 & 5.845 & $* * *$ & REJECTED \\
\hline Stress & $<---$ & STR & 0.743 & .552 & & & & REJECTED \\
\hline Positive & $<--$ & STR & 0.595 & .354 & 0.088 & 8.673 & $* * *$ & REJECTED \\
\hline Counselor & $<---$ & STR & 0.571 & .326 & 0.085 & 8.333 & $* * *$ & REJECTED \\
\hline Technique & $<---$ & STR & 0.579 & .335 & 0.088 & 8.484 & $* * *$ & REJECTED \\
\hline Balance & $<---$ & STR & 0.56 & .314 & 0.082 & 8.227 & $* * *$ & REJECTED \\
\hline $\begin{array}{l}\text { Recoginitio } \\
\mathrm{n}\end{array}$ & $<---$ & STR & 0.523 & .278 & 0.084 & 7.71 & $* * *$ & REJECTED \\
\hline
\end{tabular}

\begin{tabular}{|c|c|c|c|c|c|c|c|l|}
\hline Irritable & $<--$ & STRS & 0.409 & .168 & & & & REJECTED \\
\hline Sleeping & $<--$ & STRS & 0.886 & .784 & 0.345 & 6.837 & $* * *$ & REJECTED \\
\hline Unhappy & $<---$ & STRS & 0.394 & .155 & 0.118 & 8.226 & $* * *$ & REJECTED \\
\hline Appetite & $<---$ & STRS & 0.854 & .728 & 0.35 & 6.788 & $* * *$ & REJECTED \\
\hline Relatives & $<---$ & STRS & 0.795 & .633 & 0.329 & 6.67 & $* * *$ & REJECTED \\
\hline
\end{tabular}

The Table 4 showed the path coefficient of Stress Relievers with improvement of Stress free environment (SFE)had been loaded strongly with 0.743 and produces strong positive impact in establishing the stress free environment at work place, thereby reduces stress among the ITES Employees in trichy city. Similarly the other sub scale items of Stress Relievers namely adoption of Positive stress, Counselor, Employee Recognition were loaded heavily with $0.595,0.571,0.579,0.56,0.523$ respectively with a high significance $\mathrm{P}$-value $(\mathrm{P}<0.001)$ which in turn promotes the stress free environment at work place, thereby positively reduces the stress level of ITES Employees. TheTable 4.2 showed the path coefficient of Stress with Sleeping had been strongly loaded with 0.886 and produces strong impact in raising the stress level of ITES Employees. Similarly the other sub scale items of Stress namely Irritable, Unhappy, Appetite and Relatives were loaded heavily with 0.409 , $0.394,0.854$ and 0.795 respectively with a high significance $\mathrm{P}$-value $(\mathrm{P}<0.001)$ which in turn raises the stress level of ITES Employees. Thus, highly significant direct effect of Stress on its subscale items showed that ITES Employees had experienced individual related issues in ITES Companies in Trichy.

The stress level of ITES Employees at these places was found at higher level due to presence of stress relief at their work places. The Stress relievers had been enhanced with various factors namely Environmental factors, Organizational factors and Individual factors. These latent variables were influenced strongly by six sub scale observed variables each and promote stress relievers in ITES Employees. This was tested and proved strongly in SEM analysis. The stress relievers would be compensated and stress level of ITES Employees would be reduced positively by adoption of various stress relieving measures. The result of SEM analysis for the Stress \& Stress Relievers model supported that the suggested Stress reducing measures would positively be employed as stress busters in bringing down the stress level of ITES Employees. Taking everything into account, the outcome has demonstrated that Environmental factor, Organizational factor and Individual factor have effectively contributed towards free minded environment while adoption of various Stress Reliever measures promotes free minded environment in ITES Employees in Trichy city.

\section{CONCLUSION}

The study also brought out that Stress free environment could be the very effective stress reliever with strong loading of (0.743), Positive stress (0.595), Counselor (0.571), Stress 
Relief Technique (0.579) and Employee Recognition (0.523). This followed by other stress reliever techniques positive influence to reduce the stress level of ITES Employees.

Stress Reliever Variable cite Stress free environment, Counselor, Positive stress, Employee recognition, Work life balance and Stress relief technique had an impact in this study and effective stress reliever (see table 4.2) Researcher had learned the stress management techniques as important proved to be very effective stress relievers. These stress busters had positive influence on stress level of ITES Employees and it also generates the stress free work environment at Trichy

It is also recommended that ITES Employees are trying to come out of stressful situation by adopting coping strategies such as cultivating belief in self, cultivating positive habits promoting the norm of small family, Employees are offered a weekly, one-hour stress management session focusing on mental relaxation techniques, cognitive restructuring exercises and coping skills to handle stress, including work-related stress

An important component of stress management programs is relaxation centers that are analogues to fitness centers. Therefore the design strategy included support spaces such as meditation, exercise and relaxation rooms. These rooms would provide employees with comfortable, stress free venues to enhance creativity and productivity.

\section{REFERENCES}

1. Darton.K, “How to manage stress. MIND (National Association for mental health). London”, 2012

2. Jac J.L Van der Klink, Roland WiBBlank, Aart H.Schene. and Frank J.H Van Dijk, "The Benefits of Interventions for Work Releated Stress" American Journal of Public health Volume(91) Issue No 2, 2001, pp: 270-276

3. Sudhakar and Sudharani Ravindran, "Work Life Balance Options and Hindering factors An Investigation among an ITES Sector Firm" Summer Internship Society Volume II Issue -I, 2010, pp 121-126

4. Joseph OnyebuchukwuIdoko, Benedict Chico Emerenwa Agoha, Adeniyi SholarinMuyiwa, Oyeyemi Adeyemi Kunle, "Stress and Its management stages of stress", 2011.

5. Kousalya and Revathi, "The employee Motivation and stress management" Global Research Analysis Volume 2 Issue 4, 2013 , pp 193-194.

6. Jessica A. Pakan, "Counseling to Reduce Stress and Anxiety: A Mixed Methods Study" (2015). Counselor Education Capstone. 3, 2015, pp 1-31

7. Parminder Walia, "Gender and Age as Correlates of Work-Life Balance" Journal of Organization and Human Behaviour Volume 4 Issue 1, 2015

8. Omar Fayaz Khan, Asifiqbal Fazili, "Work Life Balance: A Conceptual Review" Journal Of Strategic Human Resource Management Volume 5 Issue 2, 2016 